\title{
Comentario a propósito del Borrador del Anteproyecto de Ley por el que se establece la normativa básica del comercio y tenencia responsable de perros y gatos ${ }^{1}$
}

Cristina Bécares Mendiola ${ }^{2}$

\section{RESUMEN:}

Actualmente se ha hecho público el Borrador del Anteproyecto por el cual se regulará la tenencia responsable de perros y gatos a nivel estatal y son varias las cuestiones que nos surgen.

¿Cómo afectará la normativa en el ámbito autonómico? ¿Qué aspectos regula? ¿Da respuesta a todas las necesidades existentes en cuanto a la regulación de la tenencia de perros y gatos?

A través de este comentario analizaremos el Borrador, destacando aquellos aspectos más novedosos o aquellos que el legislador omite.

\section{SUMARIO:}

1. Configuración del sistema

2. Situación actual en el ámbito administrativo del Derecho Animal

3. Motivación de la nueva regulación

4. Ámbito de aplicación

5. Novedades destacables

6. Aspectos no regulados

7. Conclusiones

\footnotetext{
${ }^{1}$ http://www.derechoanimal.info/bbdd/Documentos/1434.pdf

${ }^{2}$ Abogada en ejercicio. Profesora asociada a la UAB. Licenciada en Derecho y Criminología. Máster en Derecho Animal y Sociedad (1ª edición). Miembro del SGR grupo de investigación ADS (Animales, Derecho y Sociedad), Universitat Autònoma de Barcelona. http://www.derechoanimal.info/images/pdf/CV-Alumni-Cristina-Becares.pdf
} 
El texto que se comenta a continuación, no parece precisamente un modelo de estilo y técnica legislativa, por lo que el lector, de la lectura del mismo, es probable que extraiga más dudas que certezas. No obstante, se hará un comentario del Proyecto para acercar al jurista y al público en general, el contenido de una normativa que, sin duda era imprescindible que el legislador abordara.

\section{Configuración del sistema:}

Establece el artículo 148 de la Constitución Española que las comunidades autónomas podrán asumir competencias sobre determinadas materias, entre las que se incluye la gestión en materia de protección del medio ambiente, pudiendo ampliar sus competencias mediante la reforma de su Estatutos, siempre y cuando respeten las competencias exclusivas atribuidas al Estado.

Es importante destacar que toda competencia que no se haya asumido por la Comunidad Autónoma a través de su Estatuto corresponderá al Estado ${ }^{3}$. $\mathrm{Y}$, en caso de conflicto de normativas en competencias que sean exclusivas de una Comunidad, prevalecerá la normativa autonómica, siendo el derecho estatal supletorio.

Ante esta configuración del sistema, encontramos que sólo los Estatutos Autonómicos de Catalunya ${ }^{4}$ y Andalucía ${ }^{5}$ asumen las competencias específicas referentes a protección animal.

\section{Situación actual en el ámbito administrativo del Derecho Animal:}

A pesar de la regulación fijada en la Constitución Española, encontramos que actualmente todas las Comunidades Autónomas y la ciudad autónoma de Ceuta han creado normativas para regular el derecho sustantivo en materia de tenencia de animales.

\footnotetext{
${ }^{3}$ Tal y como prevé el artículo 149.3 de la Constitución Española

${ }^{4}$ En su artículo 116.1.d)

${ }^{5}$ En su artículo 48.3.a)
} 
La existencia de tal pluralidad de normas referentes a la tenencia y protección animal puede conllevar inseguridad jurídica, ya que una misma acción u omisión puede ser (o no) sancionable en diferentes comunidades, del mismo modo que un mismo hecho puede tener unas $u$ otras consecuencias dependiendo de en qué comunidad nos encontremos.

En el ámbito Estatal, actualmente, no existe una normativa-marco que regule la tenencia y protección de los animales de compañía, pero ello cambiará con la Ley que se está desarrollando. Durante el mes de Junio de 2014, el Ministerio de Agricultura, Alimentación y Medio Ambiente (MAGRAMA), ha hecho público el Borrador del Anteproyecto de Ley por el que se establece la normativa básica del comercio y tenencia responsable de perros y gatos; y a través de este borrador podemos tener conocimiento de las líneas de actuación de lo que será la Ley.

Debemos tener en cuenta que el Borrador aún debe pasar por una serie de fases hasta que sea aprobado, pudiendo verse modificado durante el trámite.

\section{Motivación de la nueva regulación:}

Encontramos la motivación de esta nueva Ley en la exposición de motivos, haciendo referencia al aumento de perros y gatos, y los beneficios que pueden reportar al ser humano.

El ejercicio de una tenencia no responsable por parte de todos los propietarios motiva que sea necesaria la regulación unos estándares mínimos en la protección y tenencia animal.

Asimismo, es necesario regular teniendo en cuenta la normativa existente en el marco de la Unión Europea en el ámbito del comercio de animales, regulando de este modo las actividades relacionadas con dicho comercio.

\section{4. Ámbito de aplicación:}

Como su propio nombre indica, esta Ley será de aplicación únicamente a perros y gatos, omitiendo la tenencia de otros animales que podamos considerar de compañía o domésticos. Dentro de este ámbito, se excluyen 
expresamente los animales que sean propiedad de los Ministerios de Defensa o Interior, y los pertenecientes a las Fuerzas y Cuerpos de Seguridad en cualquiera de sus ámbitos territoriales.

A grandes rasgos, y teniendo en cuenta los animales a los que va destinada la regulación, las finalidades de la Ley serán las de regular la tenencia responsable, el bienestar animal y el comercio.

\section{Novedades destacables:}

Se trata de una Ley novedosa, que lleva a cabo una serie de prohibiciones que otras normativas a nivel autonómico o local no llevan a cabo. Cabe destacar:

- Prohibición de mutilación, de este modo queda regulado a nivel nacional que a ningún perro o gato se le pueda amputar ningún miembro.

- Prohibición de utilización en espectáculos o como reclamo publicitario: Actualmente todas las comunidades, excepto Asturias y Cantabria ya recogían esta prohibición ${ }^{6}$.

- Prohibición de la comercialización de animales en tiendas de mascotas: De este modo se fija que los perros y gatos sólo podrán ser adquiridos a través de criador o establecimientos de acogida, no pudiendo existir intermediarios. Para llevar a cabo esta novedad, la Ley prevé un período transitorio de seis meses, por lo que de entrar en vigor las tiendas dispondrían de tiempo suficiente para adaptarse a la prohibición.

- Previsión de la figura del contrato de donación, el cual podríamos asimilar a la figura de la adopción de animales, a la cual se hace referencia en diversas ocasiones a lo largo del texto legislativo.

- Obligatoriedad de entrega de los animales con identificación, lo que podrá ayudar a disminuir los casos de abandono animal.

\footnotetext{
${ }^{6}$ Para más información: Comentario a propósito de la prohibición de utilizar animales en sorteos o como reclamo publicitario en las leyes de protección animal
} 
- Bases mínimas de bienestar animal en la tenencia de perros y gatos, de manera que se pueden garantizar unos estándares básicos para estos animales.

- Obligatoriedad de informar en el contrato de donación de aspectos como la esperanza de vida del animal, estimación de gastos anuales de la tenencia en cuanto a tratamientos y alimentación; a través de esta previsión el propietario del animal podrá ser consciente de la responsabilidad que asume al adoptar el perro o gato, sin que posteriormente pueda apelar a argumentos como el desconocimiento del coste de sostenimiento del animal.

- Obligatoriedad de solicitar la inclusión en el Registro de Núcleos Zoológicos si se tienen más de dos lebreles o sus cruces destinados a la caza, presumiendo como tales aquellos que sean de quien tenga o haya tenido licencia de caza en los últimos cinco años; a través de esta nueva obligación se podrá llevar un mayor control de los perros que puedan ser destinados a las actividades de caza.

- Regulación del transporte de perros y gatos, estableciendo en qué condiciones deberán viajar, diferenciado si nos encontramos ante el transporte que pueda realizar cualquier particular o ante el realizado por empresas privadas.

- Obligatoriedad de comunicar la pérdida de un animal en un plazo máximo de siete días, a partir de entonces se entenderá que es un animal abandonado.

- Establecimiento de dos categorías diferenciadas de criador, por una parte el habitual, considerando como tal aquella persona que tiene más de cinco animales destinados a la donación o comercialización por cualquier medio autorizado (Internet incluido), o más de una camada al año; y por otra parte el ocasional, que será aquella persona que también tiene animales destinados a la donación o comercialización por cualquier medio autorizado (Internet incluido), pero en este caso menos de cinco o una sola camada al año.

\section{Aspectos no regulados:}

Si bien es cierto que tradicionalmente perros y gatos son los animales de compañía por excelencia, existen otra serie de animales domésticos o de compañía que quedan excluidos de la regulación de protección y consecuentemente de la fijación de estándares mínimos de bienestar. 
Por otra parte, cabe hacer referencia a la poca concreción que se hace del concepto "maltrato animal", por lo que tendremos que acudir a la interpretación que haga la administración de este concepto.

La Ley tiene una serie de carencias que prevé serán reguladas a través de una serie de reglamentos que se desarrollarán en un período de entre seis meses y dos años tras la entrada en vigor de la normativa. Esta falta de concreción de una serie de aspectos conlleva inseguridad jurídica, más aun teniendo en cuenta los cambios políticos que puedan producirse y la dilación temporal que puedan sufrir dichos desarrollos normativos.

Dichas carencias las vemos ejemplificadas a la hora de no concretar la forma de llevar a cabo la identificación de los animales, determinando que se hará "en función de la edad del animal, según se haya determinado por la autoridad competente" ${ }^{7}$ " "en los plazos, forma y condiciones establecidos por la autoridad competente" ${ }^{\text {. }}$.

La Ley exige la inscripción en el Registro de criadores y la declaración responsable únicamente para los criadores habituales, no fijando apenas obligaciones para aquellos criadores denominados como "ocasionales". Desde mi punto de vista no se está regulando de forma directa la actividad económica de dichos criadores ocasionales, cuando de su actividad podrán obtener un beneficio económico, que si bien será inferior al de los criadores habituales, si merece una especial regulación distinta a la del resto de particulares.

Otro aspecto no previsto en la normativa es la obligatoriedad de inscripción de los perros y gatos en los censos municipales.

En el ámbito de las adopciones o donaciones, se regulan las realizadas por los establecimientos de acogida, pero no se hace referencia expresa a aquellas que puedan ser realizadas por asociaciones sin ánimo de lucro.

En cuanto al sistema de sanciones, existe una carencia en cuanto al establecimiento de sanciones accesorias. En comunidades autónomas como la de Aragón se prevé que al sancionado se le pueda imponer de forma accesoria la prohibición de tenencia o adquisición de animales, otras comunidades como

\footnotetext{
${ }^{7}$ Según el artículo 5.2.b)

${ }^{8}$ Según el artículo 7.1
} 
Andalucía, Castilla-La Mancha y Navarra, establecen la prohibición de tenencia de animales; y por otra parte Asturias, la Comunidad Valenciana y Euskadi prevén la prohibición de adquisición de animales por parte del sancionado. Con ello observamos que existe un avance en el ámbito autonómico que no existe en el actual anteproyecto legislativo.

\section{Conclusiones:}

Tal y como hemos podido ver, se trata de una normativa que podrá suponer un paso adelante en la regulación de la tenencia animal en comunidades que hasta ahora no habían adquirido un compromiso tan amplio de la regulación del bienestar animal.

A pesar de ello, desde mi punto de vista el anteproyecto legislativo es excesivamente laxo en cuanto a los aspectos regulados y las sanciones previstas. Centrándonos en las sanciones, se omiten las sanciones en casos de maltrato animal, tanto activo como pasivo, no previendo graduación en función de la gravedad. Y. en cuanto a las sanciones, destacar que se prevé una bonificación del $40 \%$ si se abona la multa en plazo de 15 días, por lo tanto podríamos encontrarnos que infracciones como exhibir perros y gatos como reclamo suponga sólo pagar $60 .-€$ de multa, lo cual resulta irrisorio.

Destacar también el uso que se realiza del concepto "eutanasia", ya que está hablando de dar muertes mediante eutanasia a los animales abandonados tras el plazo de treinta días desde su ingreso, sin tener en cuenta que nos encontramos ante casos de sacrificio.

Al hilo de esto, cabe hacer mención a que la habilitación para sacrificar los animales abandonados en dichos términos, supone un paso atrás en comparación a la regulación prevista en Catalunya, siendo ésta la única que prohíbe expresamente el sacrificio de animales a través del artículo 11 del Decreto Legislativo 2/2008, de 15 de abril ${ }^{9}$.

Por último y no menos importante, hacer mención a la problemática competencial con la que nos encontraremos en caso de que entre en vigor en los actuales términos, y es que como comentábamos anteriormente sólo dos comunidades tienen atribuida la competencia en esta materia a través de sus

\footnotetext{
${ }^{9}$ http://www.derechoanimal.info/bbdd/Documentos/458.pdf
} 
estatutos, por lo que nos preguntamos ¿Qué ocurrirá con las normativas actuales del resto de comunidades autónomas? ¿Quedarán derogadas de forma automática al no haber previsto en sus estatutos de forma expresa a asunción de dichas competencias? Y es que, de aprobarse esta ley estatal, teniendo en cuenta la prevalencia de las normas del Estado en materias no asumidas por las comunidades, indirectamente quedarán vacías de contenido en términos de aplicación.

Terrassa, a 6 de julio de 2014 